\title{
Ergonomic Evaluation of Workload in Imbalanced Lower Limbs Postures
}

\author{
Eun-Sik Kim, Hoon-Yong Yoon \\ Department of Industrial and Management Systems Engineering, Dong-A University, Busan, 604-714
}

\begin{abstract}
Objective: The purpose of this study is to compare the workload level at each lower limbs posture and suggest the ergonomic workstation guideline for working period by evaluating the imbalanced lower limbs postures from the physiological and psychophysical points of view. Background: Many workers like welders are working in various imbalanced lower limbs postures either due to the narrow working conditions or other environmental conditions. Method: Ten male subjects participated in this experiment. Subjects were asked to maintain 3 different lower limbs postures(standing, squatting and bending) with 3 different working conditions(balanced floor with no scaffold, imbalanced floor with $10 \mathrm{~cm}$ height of scaffold, and imbalanced floor with $20 \mathrm{~cm}$ height of scaffold). EMG data for the 4 muscle groups(Retus Femoris, Vastus Lateralis, Tibialis Anterior, Gastrocnemius) from each lower limbs posture were collected for 20 seconds every 2 minutes during the 8 minutes sustaining task. Subjects were also asked to report their discomfort ratings of body parts such as waist, upper legs, lower legs, and ankle. Results: The ANOVA results showed that the EMG root mean square(RMS) values and the discomfort ratings(CR-10 Rating Scale) were significantly affected by lower limbs postures and working time $(p<0.05)$. The correlation was analyzed between the EMG data and the discomfort ratings. Also, prediction models for the discomfort rating for each posture were developed using physical condition, working time, and scaffold height. Conclusion: We strongly recommend that one should not work more than 6 minutes in a standing or squatting postures and should not work more than 4 minutes in a bending posture. Application: The results of this study could be used to design and assess working environments and methods. Furthermore, these results could be used to suggest ergonomic guidelines for the lower limbs postures such as squatting and bending in the working fields in order to prevent fatigue and pain in the lower limbs body.
\end{abstract}

Keywords: Imbalanced lower limbs posture, EMG data, CR-10 rating, Prediction model

\section{Introduction}

산업현장 및 서비스 업종에서 많은 작업들이 기계화 및 자동화가 되었음에도 불구하고 비정형 작업의 경우 아직까 지 많은 작업들은 인력 작업에 의존하고 있는 실정이다. 인 력 작업의 경우 반복 작업, 부적절한 자세, 과도한 힘 등에 따라 과부하가 발생될 수 있으며, 이로 인해 작업 관련성 근골격계질환을 유발할 수 있는 문제점을 내포하고 있다.
이러한 작업관련 근골격계질환 유발의 요인 중에서도 부적 절한 작업 자세의 경우가 주요 요인으로 꼽히고 있다.

근골격계질환의 주요 요인인 부적절한 작업 자세에 대한 연구로서 Van Wely(1970)와 Grandjean et al.(1977)은 부적절한 작업 자세에 의해 발생 가능한 질환 및 통증 부위 에 대해 제시하였고, Genaidy et al.(1995)은 손목(7자세), 팔꿈치(5자세), 어깨(5자세), 목(5자세), 허리(5자세) 등의 부위에서 총 27 가지의 비중립적 자세에 대한 주관적 불편도 (10점 척도)를 기준으로 서열을 정의하였다. Westgaard et

Corresponding Author: Hoon-Yong Yoon. Department of Industrial and Management Systems Engineering, Dong-A University Busan, $604-714$.

Mobile: 010-2369-9535, E-mail: yhyoon@dau.ac.kr

Copyright@2011 by Ergonomics Society of Korea(pISSN:1229-1684 eISSN:2093-8462). All right reserved. 
al. (1984)은 어깨와 목 부위에서 정적인 자세를 장시간 지 속하는 작업자들에게서 어깨와 목 부위에서 근골격계질환의 발병률이 상대적으로 높은 것으로 보고하였으며, 근골격계질 환과 근무 년수, 나이에 대해 상관성이 높다고 보고하였다. Oberg et al. (1994)은 EMG의 MPF 분석을 통해 앉은 자 세에서 팔이 어깨위로 올라가는 작업 자세에서의 근육 피로 도를 조사하여 주관적 불편도 $(\mathrm{CR}-\mathrm{scale})$ 와 근육 피로도와 의 상관성에 대해 연구하였다. 이와 같이 근골격계질환의 주 요 요인인 작업 자세에 대한 연구는 주로 상체인 목, 어깨, 허리, 팔꿈치, 손목 등의 부위에 집중되었으며, 이에 반해 하지에 대한 연구는 상체에 비해 연구가 활발하게 이루지 지 않았다. 하지만 하지 자세는 전신의 안정성 (stability) 과 동작성(mobility)에 영향을 미치기 때문에 하지의 자세에 따라서 전신의 작업 자세 부하가 영향을 받게 되므로 중요 하다. 또한, 미국, 영국 등의 선진국의 경우 신체 부위별로 질환자수를 구분하면 매년 하지 관련 근골격계질환자가 전 체 근골격계질환자의 $10 \%$ 이상을 차지하고 있으며, 시간 이 지남에 따라 목, 어깨, 상지, 허리 등의 다른 부위에 비 해 감소율이 가장 적은 부위로 나타남에 따라 외국의 경우 하지 관련 근골격계질환에 관한 연구가 점점 증가하는 추세 를 보이고 있다. 그 결과, 근골격계질환의 유발과 하지 자세 간의 상관성은 Van Wely (1970), Grandjean et al. (1977), Gallagher et al.(1988)의 여러 연구에서 보고하고 있으며, 하지 자세를 근골격계질환의 주요위험요인 중 하나로 보고 하고 있다.

그 중에서도 쪼그려 앉은 자세 및 무릎 앉은 자세는 30분 이상 지속되거나 하루 작업시간 중 2 시간 이상 취해질 경우 무릎 관련 근골격계질환의 주된 요인으로 많은 연구들을 통 해 분류되었다(Cooper, 1994; Coggon, 2000; Nahit, 2001; Baker, 2003; Zhang, 2004; Jensen, 1996).

그 결과, 영국의 $\mathrm{HSE}$ 에서는 2009년에 Lower limb $\mathrm{MSD}$ 연구보고서를 발표하여 200건 이상의 역학적 연구 (epidemiologic studies) 문헌에 대한 조사 결과를 바탕으 로 하지 관련 근골격계질환의 원인과 범위를 정의하고 예방 하기 위한 가이드 라인을 제시하였다. 하지에 관한 국내 연 구로 Lee et al. (1998)은 쪼그려 앉은 작업 자세 작업용 받 침대의 유무 및 높이와 작업 지속시간에 대해 주관적 불편 도를 이용하여 연구하였고, 2002년에는 다양한 하지 자세 (31가지)에 대해 정적인 자세 유지 후 주관적 불편도를 이 용하여 평가하여 작업 자세간에 부하 수준을 비교하였다. Hong et al. (2009)는 13 가지의 하지의 불균형 작업 자세에 대한 주관적 불편도 및 근전도 평가를 실시하였다.

하지 관련 국내 - 외 연구의 대부분은 연구가 오른발 왼발 의 균형 상태에 대해 이루어졌으며, 불균형 상태에 관한 연 구 또한 피실험자의 체중을 한발에 집중시켰을 뿐 오른발
왼발의 높이가 다른 자세에 대한 연구는 아직 이루어지고 있지 앉은 상태이다. 그러나 우리 나라의 경우 조선업, 중공 업, 제조업 등 다양한 산업현장에서 쪼그린 자세, 무릎 앉 은 자세 등을 비롯한 다양한 하지 자세가 장시간 노출되어 있으며, 금형 보전 수리 및 설비 보전 등의 비정형 작업과 같은 경우 오른발, 왼발의 높이가 다른 불균형 하지 자세가 Figure 1 과 같이 빈번하게 나타나고 있기 때문에 이에 대 한 연구가 필요하다.

따라서 본 연구에서는 오른발과 왼발의 높이가 다른 하지 불균형 자세에 대해 주요 근육의 활성도와 주요 부위의 주관 적 불편도를 평가하여 다양한 하지 자세간의 부하 수준을 비교 및 작업 지속시간에 대한 인간공학적 작업 지침을 제시 하기 위한 평가를 실시하고자 한다.

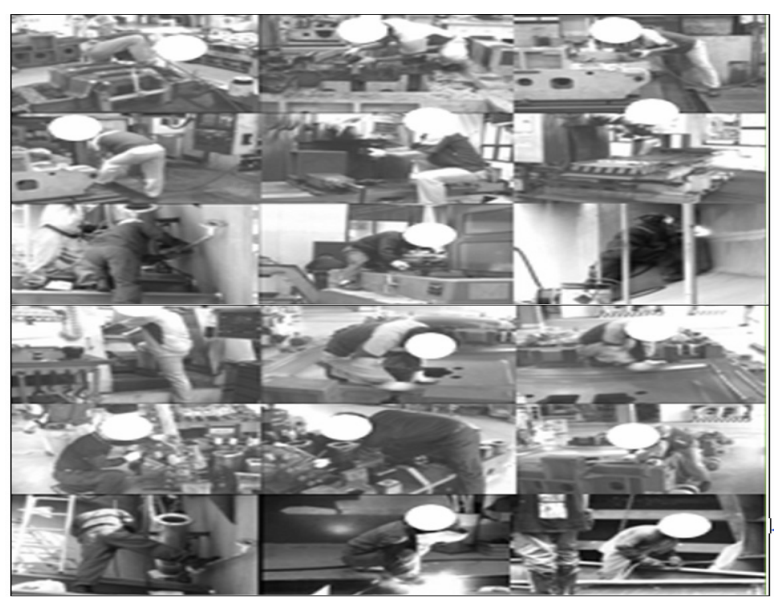

Figure 1. The example of Imbalanced Lower Limbs Postures

\section{Method}

\subsection{Subjects}

본 연구에서는 20 대 남성 10 명을 대상으로 실험을 실시 하였다. 실험 전 과거에 하지 및 허리 부위에 병력체크를 실 시하고 과거 운동선수 경력이 있는 사람은 제외하였다. 피실 험자는 실험에 앞서 적어도 2 시간 전에는 음식물의 섭취와 담배나 술은 삼가도록 하였으며, 또한 격렬한 육체적인 활동 을 피하도록 하였다.

실험에 참여한 피실험자의 평균 연령은 24.9(土2.12)세 이고 신체적 조건은 <Table 1 >과 같다. 
Table 1. Anthropometric characteristics of the study population

\begin{tabular}{c|c|c}
\hline Item & Mean & SD \\
\hline Height $(\mathrm{cm})$ & 174.06 & 0.14 \\
\hline Weight $(\mathrm{kg})$ & 67.39 & 0.34 \\
\hline leg length $(\mathrm{cm})$ & 94.47 & 0.11 \\
\hline Knee height $(\mathrm{cm})$ & 47.0 & 0.03 \\
\hline Foot length $(\mathrm{cm})$ & 25.37 & 0.03 \\
\hline Foot breadth $(\mathrm{cm})$ & 9.43 & 0.01 \\
\hline
\end{tabular}

\subsection{Experimental design}

본 연구에서는 하지 자세를 선 자세, 쪼그려 앉은 자세, 무릎 앉은 자세의 3 수준과 발판 높이 $0 \mathrm{~cm}, 10 \mathrm{~cm}, 20 \mathrm{~cm}$ 의 3 수준 그리고 작업시간을 2 분, 4 분, 6 분, 8 분의 4 수준을 각 각 독립 변수로 선정하였다. 각 자세의 무릎 각도 및 발목 각도, 몸통 각도 그리고 무게에 대한 변수 등을 통제 변수로 설정하여 실험을 수행하였다. 종속 변수로는 허리와 오른발 의 윗다리, 아랫다리, 발목 등의 4 부위에 대한 주관적 불편 도, 오른발의 대퇴직근, 외측광근, 비복근, 전경골근 등의 4 개 근육에 대한 근전도값 등을 사용하였다. <Table 2>는 본 연구의 실험 변수를 요약한 것이다.

Table 2. Experimental variables and levels for analysis of Workload in Imbalanced Lower Limbs Postures

\begin{tabular}{c|c}
\hline Variables & Levels \\
\hline \multirow{3}{*}{$\begin{array}{c}\text { Independent } \\
\text { variables }\end{array}$} & Posture: standing(st), squatting(sq), bending(be) \\
\cline { 2 - 2 } & Scaffold height: 0cm, $10 \mathrm{~cm}, 20 \mathrm{~cm}$ \\
\cline { 2 - 2 } & Time: $2 \mathrm{~min}, 4 \mathrm{~min}, 6 \mathrm{~min}, 8 \mathrm{~min}$ \\
\cline { 2 - 2 } $\begin{array}{c}\text { Control } \\
\text { variables }\end{array}$ & Posture: sitting \\
\cline { 2 - 2 } & Knee angle \\
\cline { 2 - 2 } & Ankle angle \\
\cline { 2 - 2 } & Trunk angle \\
\hline \multirow{4}{*}{$\begin{array}{c}\text { Dependent } \\
\text { variables }\end{array}$} & Weight load: $2 \mathrm{~kg}$ \\
\cline { 2 - 2 } & Rnvironment(temperature, humidity) \\
\hline
\end{tabular}

본 연구에서 평가된 하지 자세는 각 발판 높이에서의 선 자세, 쪼그려 앉은 자세, 무릎 앉은 자세와 기준 자세인 의 자에 앉은 자세를 포함하여 총 10 가지의 자세이다. 기존 연 구들의 하지 불균형 자세는 오른발 왼발의 높이가 같은 상 태에서 피실험자의 체중을 한쪽 다리에 집중시킨 자세인 반 면, 본 연구에서의 하지 불균형 자세는 오른발과 왼발의 발
판의 높이가 다른 자세이다. 실제 산업현장의 비정형 작업 자세에 대해 조사한 결과 작업장소의 협소함 또는 기타 환경 적인 요인으로 작업자는 오른발과 왼발의 발판 높이가 서로 다른 환경적 조건에서 작업이 실시되고 있으며, 실제 산업현 장과 동일한 조건을 부여하기 위해 각 발판의 높이를 측정한 결과 $10 \sim 20 \mathrm{~cm}$ 이었다.

따라서 본 연구의 하지 자세는 선 자세, 쪼그려 앉은 자 세, 무릎 앉은 자세 각각에 높이 변수로써 오른쪽 다리에 $0 \mathrm{~cm}, 10 \mathrm{~cm}, 20 \mathrm{~cm}$ 발판을 부여하였다. 선 자세의 경우 양발 을 어깨 너비만큼 벌린 다음 오른발을 발 직선길이만큼 앞으 로 내민 후 체중을 오른발에 집중시킨 자세이며, 쪼그려 앉 은 자세의 경우 양발을 어깨 너비만큼 벌린 후 양 발바닥을 바닥에 고정시켰으며 슬관절이 $150^{\circ}$ 이상이 되도록 하였고 무를 앉은 자세의 경우 오른쪽 발가락이 접힌 상태에서 엉덩 이를 오른쪽 뒷꿈치에 붙인 자세이다.

자세에 대한 무게 부하는 현재 산업현장에서 많이 사용하 고 있는 드릴, 렌치, 해머 등 수공구의 무게 범위가 대략 $1 \sim 2 \mathrm{~kg}$ 전후임을 조사하였고, 또한 인간공학적 수공구 설 계 기준이 $1.7 \mathrm{~kg}$ 임을 감안하여 작업자들이 실제 산업현장에 서 무게 부하로 많이 느낄 수 있는 무게인 $2 \mathrm{~kg}$ 으로 선정하 였다.

\subsection{Experiment procedure and method}

실험에 앞서 피실험자에게 실험의 목적에 대해 상세한 설 명이 이루어졌고, 원활한 실험이 이루어질 수 있도록 실험방 법과 유의사항을 전달하였다. 피실험자에 대한 교육이 끝난 뒤에 피실험자의 성명, 나이, 병력여부 및 운동여부 등의 기 본조사가 이루어졌으며, 키, 몸무게 등의 인체측정 이루어 졌다. 그 후 피실험자에게 실험 자세에 대해 설명 및 시범을 보였고 피실험자가 실험장비와 실험 조건에 익숙해지도록 친숙기간을 제공하였다. 적응 훈련이 끝난 피실험자를 대상 으로 무작위로 할당된 실험순서에 따라서 8분간 정적 자세 를 취하도록 하였다. 8 분간 정적 자세를 취하는 동안 매 2 분 마다 피실험자는 자세를 유지한 상태에서 주관적 불평도 평 가 및 $\mathrm{EMG}$ 측정을 실시하였다. 또한 각 실험간에는 피로에 의한 영향을 최소화하기 위해 1 회의 실험 실시 후 침대에 누운 상태에서 최소 20 분간의 휴식이 주어졌고 실험 도중 피실험자가 주어진 실험 조건을 유지하지 못하였을 경우에 는 재 실험을 실시하였다.

근력측정은 $\mathrm{BTE}$ 사의 PRIMUS를 사용하여 $\mathrm{ABC}$ of $\mathrm{EMG}$ (2005)을 참고하여 대퇴사두근의 근력, 비복근의 근력, 전 경골근의 근력 등을 측정하였다. 대퇴사두근의 경우 슬관절 의 신전작용의 주동근으로서 근력측정 자세는 의자에 앉은 다음 슬관절 각도 $45^{\circ}$ 인 상태에서 신전할 시의 근력을 측정 
하였고 비복근의 경우 족관절의 저측굴곡 시 주동근임에 따 라 의자에 앉아 발을 뻗은 다음 족관절이 $90^{\circ}$ 인 상태에서 족관절의 저측굴곡 시의 근력을 측정하였다. 전경골근의 경 우 족관절의 배측굴곡시 주동근으로서 선 자세에서 어깨 너 비만큼 발을 벌린 다음 족관절의 배측굴곡 시의 근력을 측 정하였다.

\subsection{Data analysis}

주관적 불편도 측정은 정적 운동에 의한 고통 및 부하를 측정할 수 있는 Borg's CR-10 scale이라 불리는 비율 척 도(rating scale)를 사용하도록 권고된다. 따라서 본 연구의 경우 8 분간의 정적 자세 동안 2 분 간격으로 10 점 척도인 Borg's CR-10 scale을 사용하여 데이터를 수집하였다. 근 피로도에 대한 접근방법은 일반적으로 스펙트럼 분석을 이 용한 평균 주파수(mean frequency), 중간 주파수(median frequency) 및 RMS(root) 매개 변수를 분석하는 것이 알 려져 있다. Basmajian(1978)은 정적 운동의 경우 근육의 피로가 누적됨에 따라 평균 주파수의 감소 및 RMS 값의 증가가 나타난다고 하였다. 따라서 본 연구의 경우 데이터 수 집은 Sampling frequency는 $1,024 \mathrm{~Hz}$ 로 측정된 Raw data 를 일차적으로 정류(Rectification)와 RMS Smoothing 처 리한 후, 이차적으로 10 520Hz Band pass filtering 처리 하여 얻어진 RMS (Root Mean Square) 값을 이용하였다. 통계적 분석은 SAS 9.1를 이용하여 분산분석 및 Tukey range test 그리고 상관분석 및 다중회귀 분석을 실시하였다.

\section{Results}

\subsection{Subjective discomfort (CR-10) for body parts}

\subsubsection{Waist}

하지 불균형 자세 $(\mathrm{P})$, 지속시간 $(\mathrm{T})$ 에 따른 허리에 대 한 주관적 불편도 분산분석의 결과는 <Table 3 >과 같다. <Table 3 >에서 나타난 바와 같이 하지 불균형 자세, 지속시

Table 3. ANOVA for CR-10 on waist by posture and time

\begin{tabular}{c|r|r|r|r|l}
\hline Source & \multicolumn{1}{|c|}{ DF } & \multicolumn{1}{c|}{ SS } & MS & F value & $\operatorname{Pr}>\mathrm{F}$ \\
\hline $\mathrm{P}$ & 9 & 147.76 & 16.42 & 15.95 & $<.001^{* *}$ \\
\hline $\mathrm{T}$ & 3 & 57.92 & 19.31 & 18.75 & $<.001^{* *}$ \\
\hline $\mathrm{P} * \mathrm{~T}$ & 27 & 14.49 & 0.54 & 0.52 & 0.9784 \\
\hline ERROR & 360 & 370.65 & 1.03 & & \\
\hline TOTAL & 399 & 590.81 & & & \\
\hline
\end{tabular}

간 간에 불편도의 차이가 유의하게 나타났으며, 하지 불균 형 자세와 작업시간의 교호작용에 대해서는 유의하지 않게 나타났다 $(\alpha=0.01)$.

Figure 2 는 각각 하지 불균형 자세, 지속시간에 따른 허 리에 대한 주관적 불편도의 평균을 나타내고 있다. 지속시간 8 분 경과시 쪼그려 앉은 자세 $(20 \mathrm{~cm})$, 무릎 앉은 자세 $(10$, $20 \mathrm{~cm}$ ) 의 경우 불편도가 3점 이상으로 나타났다. 시간이 지 남에 따라 선 자세의 경우 발판 높이에 따른 불편도의 차이 가 나타나지 않은 것에 비해 쪼그려 앉은 자세의 경우 발판 높이가 $20 \mathrm{~cm}$ 일 때 2 분 경과시부터 불편도의 차이를 나타 내며 6 분 경과시부터 발판 높이 $0 \mathrm{~cm}, 10 \mathrm{~cm}$ 간에 불편도의 차이가 나타났다. 무를 앉은 자세의 경우 지속시간 6 분까지 는 차이가 나타나지 않다가 6 분 경과시부터 예상과는 달리 $10 \mathrm{~cm}$ 의 경우 불편도가 가장 낮게 나타났고 $0 \mathrm{~cm}$ 와 $20 \mathrm{~cm}$ 가 높게 나타났다.

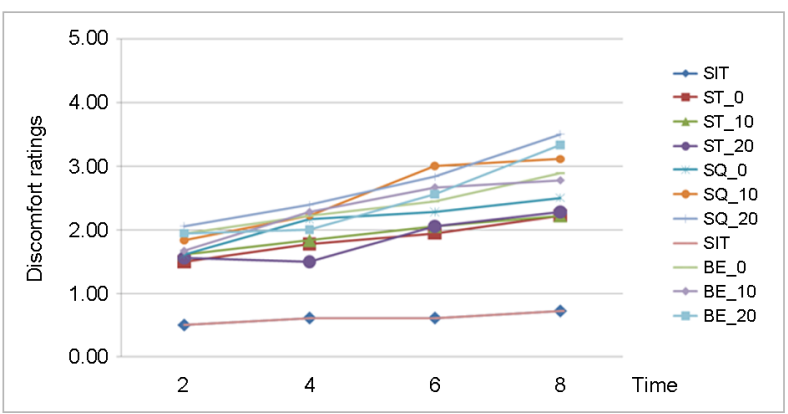

Figure 2. The average of CR-10 on waist by posture and time

선 자세의 경우 하지 불균형 자세가 허리의 비틀림에 큰 영향을 미치지 않으며, 쪼그려 앉은 자세의 경우 하지 불균 형 자세로 인한 허리 비틀림의 영향이 가장 큰 것을 알 수 있다.

무릎 앉은 자세의 경우 오른발의 슬관절을 $150^{\circ}$ 이상 구 부리는 반면 왼발의 경우 슬관절의 각도가 $90^{\circ}$ 임에 따른 오른발과 왼발의 높이 차가 발생되는데 이러한 높이 차이가 약 $10 \mathrm{~cm}$ 임에 따라 오른발에 $10 \mathrm{~cm}$ 높이의 발판을 받쳐줌 으로써 허리의 비틀림이 발생되지 않아 주관적 불편도가 가 장 낮게 나타난 것으로 추정되며, 따라서 무릎 앉은 자세의 경우 오른발에 $10 \mathrm{~cm}$ 정도의 발판을 제공하는 것이 허리의 비틀림을 예방하는 것으로 추정된다.

\subsubsection{Upper leg}

하지 불균형 자세 $(\mathrm{P})$ 별 지속시간 $(\mathrm{T})$ 에 따른 오른쪽 윗다 리에 대한 주관적 불편도 분산분석의 결과는 <Table $4>$ 와 같다. <Table 4>에서 나타난 바와 같이 하지 불균형 자세, 
지속시간 간에 불편도의 차이가 유의하게 나타났으며, 하지 불균형 자세와 작업시간의 교호작용에 대해서는 유의하지 않게 나타났다 $(\alpha=0.01)$.

Table 4. ANOVA for CR-10 on upper leg by posture and time

\begin{tabular}{c|r|r|r|r|l}
\hline Source & \multicolumn{1}{|c|}{ DF } & \multicolumn{1}{c|}{ SS } & \multicolumn{1}{c|}{ MS } & F value & $\operatorname{Pr}>\mathrm{F}$ \\
\hline $\mathrm{P}$ & 9 & 323.38 & 35.93 & 24.99 & $<.001^{* *}$ \\
\hline $\mathrm{T}$ & 3 & 124.01 & 41.34 & 28.75 & $<.001^{* *}$ \\
\hline $\mathrm{P} * \mathrm{~T}$ & 27 & 27.00 & 1.00 & 0.70 & 0.8724 \\
\hline ERROR & 360 & 517.65 & 1.44 & & \\
\hline TOTAL & 399 & 992.04 & & & \\
\hline
\end{tabular}

Figure 3 은 각각 하지 불균형 자세별 지속시간에 따른 오른쪽 윗다리에 대한 주관적 불편도의 평균을 나타내고 있 다. 선 자세의 경우 $(0 \mathrm{~cm}, 10 \mathrm{~cm}, 20 \mathrm{~cm}) 4$ 분 경과시부터 불 편도가 3 점 이상으로 나타났으며, 발판 높이 $20 \mathrm{~cm}$ 의 경우 8 분 경과시 불편도가 5점 이상으로 가장 높게 나타났다. 쪼 그려 앉은 자세의 경우 불편도가 발판 높이 $20 \mathrm{~cm}$ 의 경우 불편도가 4점 이상으로 높게 나타났으며, 발판 높이 $0 \mathrm{~cm}$ 와 $20 \mathrm{~cm}$ 의 경우 불편도의 차이가 나타나지 않았다. 무릎 앉은 자세의 경우 허리와 마찬가지로 발판 높이 $10 \mathrm{~cm}$ 의 경우 불 편도가 가장 낮게 나타났으며, 발판 높이가 $20 \mathrm{~cm}$ 의 경우 불편도의 점수가 4 점 이상으로 가장 크게 나타났다. 이것으 로 선 자세의 경우 허리와 다르게 쪼그려 앉은 자세와 무릎 앉은 자세보다 불편도가 1점 이상으로 크게 나온 것을 알 수 있는데 이것의 원인으로는 다른 자세와는 다르게 선 자세 의 경우 실험 조건상 인위적으로 체중의 중심을 오른발에 집 중시킨 결과로 추정할 수 있다. 무릎 앉은 자세의 경우 허리 와 마찬가지로 발판 높이 $10 \mathrm{~cm}$ 의 경우 불편도가 가장 낮게 난 것을 알 수 있는데 이것은 앞에서 언급한 바와 같이 $10 \mathrm{~cm}$ 높이의 발판을 받쳐 줌으로써 오른발과 왼발의 높이 차이에 대한 체중이 오른발에 집중되는 것을 예방해 주는 것 에 대한 결과로 볼 수 있다.

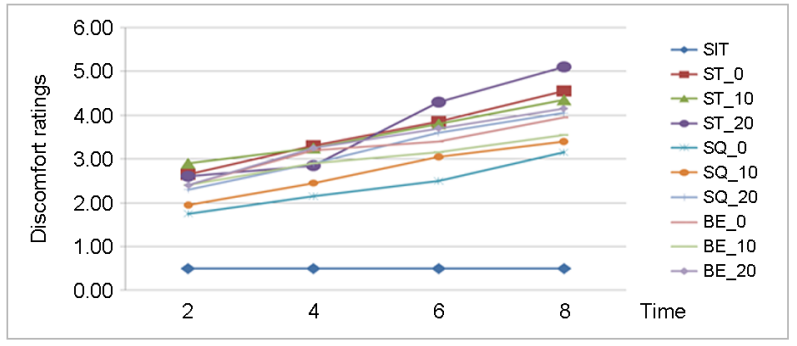

Figure 3. The average of CR-10 on upper leg by posture and time

\subsubsection{Lower leg}

하지 불균형 자세 $(\mathrm{P})$ 별 지속시간 $(\mathrm{T})$ 에 따른 오른쪽 아랫 다리에 대한 주관적 불편도 분산분석의 결과는 〈Table 5> 와 같다. <Table 5 >에서 나타난 바와 같이 하지 불균형 자 세, 지속시간 간에 불편도의 차이가 유의하게 나타났으며, 하지 불균형 자세와 작업시간의 교호작용에 대해서는 유의 하지 않게 나타났다 $(\alpha=0.01)$.

Table 5. ANOVA for CR-10 on lower leg by posture and time

\begin{tabular}{c|r|r|r|c|c}
\hline Source & \multicolumn{1}{|c|}{ DF } & \multicolumn{1}{c|}{ SS } & \multicolumn{1}{c|}{ MS } & F value & $\operatorname{Pr}>\mathrm{F}$ \\
\hline $\mathrm{P}$ & 9 & 356.83 & 39.65 & 22.91 & $<.001^{* *}$ \\
\hline $\mathrm{T}$ & 3 & 174.68 & 58.23 & 33.64 & $<.001^{* *}$ \\
\hline $\mathrm{P} * \mathrm{~T}$ & 27 & 28.51 & 1.06 & 0.61 & 0.9392 \\
\hline ERROR & 360 & 623.13 & 1.73 & & \\
\hline TOTAL & 399 & 1183.15 & & & \\
\hline
\end{tabular}

Figure 4는 각각 하지 불균형 자세별 지속시간에 따른 오른쪽 아랫다리에 대한 주관적 불편도의 평균을 나타내고 있다. 선 자세의 경우 $(0 \mathrm{~cm}, 10 \mathrm{~cm}, 20 \mathrm{~cm}) 6$ 분 경과시부터 불편도가 3점 이상으로 나타났으며, 발판 높이에 따른 불편 도의 차이가 나타나지 않았다. 쪼그려 앉은 자세와 무릎 앉 은 자세의 경우 발판 높이 $20 \mathrm{~cm}$ 에서 가장 큰 불편도를 나 타냈으며, 쪼그려 앉은 자세의 경우 2 분 경과시부터 불편도 차이를 보였고 무릎 앉은 자세의 경우 8 분 경과시 불편도 차이를 보였다. 또한, 선 자세, 무릎 앉은 자세에 비해 쪼그 려 앉은 자세 $(20 \mathrm{~cm})$ 의 경우 불편도가 5.5 점으로 가장 높 게 나타났다. 이것은 다른 자세에 비해 쪼그려 앉은 자세인 경우 무게 중심을 잡기 어려운 자세로 피실험자가 8분간 정 적 자세를 유지하기 위해 아랫다리에 지속적으로 힘을 발휘 한 것에 의한 결과로 추정될 수 있다.

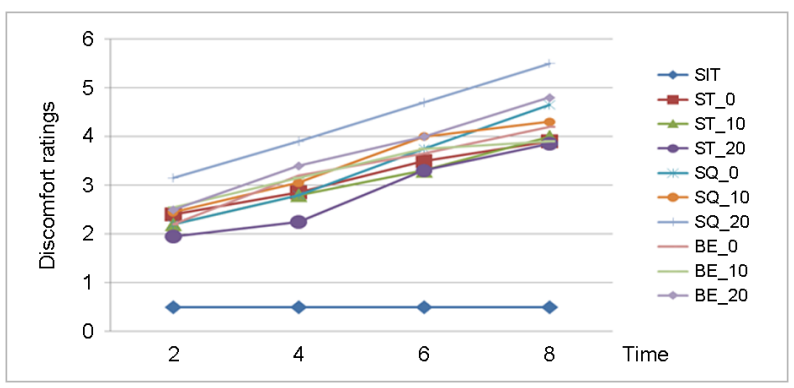

Figure 4. The average of CR-10 on lower leg by posture and time 


\subsubsection{Ankle}

하지 불균형 자세 $(\mathrm{P})$ 별 지속시간 $(\mathrm{T})$ 에 따른 오른쪽 발목 에 대한 주관적 불편도 분산분석의 결과는 <Table 6>와 같다. <Table 6>에서 나타난 바와 같이 하지 불균형 자세, 지속시간 간에 불편도의 차이가 유의하게 나타났으며, 하지 불균형 자세와 작업시간의 교호작용에 대해서는 유의하지 않게 나타났다 $(\alpha=0.01)$.

Table 6. ANOVA for CR-10 on ankle by posture and time

\begin{tabular}{c|r|r|r|r|l}
\hline Source & \multicolumn{1}{|c|}{ DF } & \multicolumn{1}{c|}{ SS } & \multicolumn{1}{c|}{ MS } & F value & $\operatorname{Pr}>\mathrm{F}$ \\
\hline $\mathrm{P}$ & 9 & 410.86 & 45.65 & 18.03 & $<.001^{* *}$ \\
\hline $\mathrm{T}$ & 3 & 132.80 & 44.27 & 17.48 & $<.001^{* *}$ \\
\hline $\mathrm{P} * \mathrm{~T}$ & 27 & 20.98 & 0.78 & 0.31 & 0.9997 \\
\hline ERROR & 360 & 911.43 & 2.53 & & \\
\hline TOTAL & 399 & 1476.07 & & & \\
\hline
\end{tabular}

Figure 5는 각각 하지 불균형 자세별 지속시간에 따른 오른쪽 발목에 대한 주관적 불편도의 평균을 나타내고 있다. 선 자세 및 무릎 앉은 자세의 경우 발판 높이에 따른 불편도 의 차이가 나타나지는 않았으나, 무릎 앉은 자세의 경우 6 분 경과시부터 불편도가 4점 이상으로 높게 나타났으며, 쪼그려 앉은 자세의 경우 4 분 경과시부터 발판 높이가 $20 \mathrm{~cm}$ 인 경 우에 발판 높이 $0 \mathrm{~cm}, 10 \mathrm{~cm}$ 와 불편도 차이가 나타났으며 8 분경과시 4.95 점으로 가장 높은 불편도가 나타났다.

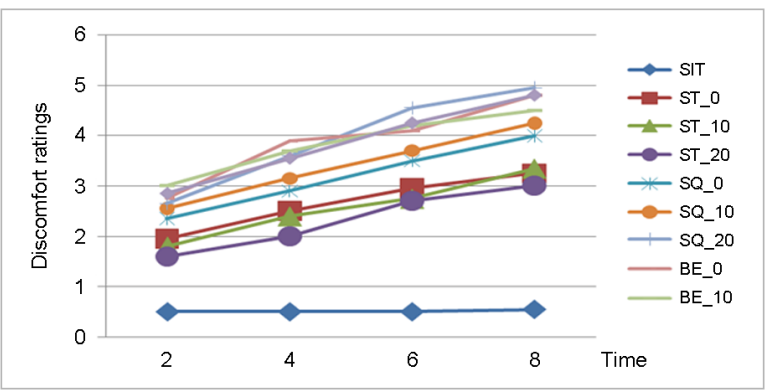

Figure 5. The average of CR-10 on ankle by posture and time

\subsection{The relationship between CR-10 result and Muscle strength}

피실험자의 하지 근력과 주관적 불편도의 상관관계분석의 결과는 <Table 7 >와 같다. 결과에서 보는 바와 같이 오른쪽 윗다리와 오른쪽 대퇴사두근 및 왼쪽 비복근 등의 근력의
경우를 제외하고는 모든 곳에서 통계적으로 유의하게 나왔 으나 상관계수 값이 모두 0.4 미만의 값으로 상관관계가 있다고 볼 수는 없다. 하지만 상관관계분석 결과 모든 부위 에서 양의 상관계수가 나타남에 따라 일반적으로 신체 부위 의 근력이 높을수록 주관적 불편도가 낮을 거라는 통념과 다 른 결과를 나타났다. 선행 연구들을 살펴보면 하지 관련 근 골격계질환을 예방하기 위해 쪼그려 앉은 자세 및 무릎 앉 은 자세 등을 지양하는 것뿐만 아니라 하지 부위에 근력을 강화시키는 것을 제언하였다. 하지만 본 실험의 결과 하지 근력이 강할수록 불편도가 높은 추세로 나타남에 따라 하지 부위 근력 강화 등은 적절하지 못한 것으로 추정된다. 본 실 험 결과의 원인으로는 하지 근력이 강화될수록 하지의 둘레 가 두꺼워 짐에 따라 수반되는 각 신체 부위의 압력 및 각 관절의 모멘트 값의 증가로 인해 불편도가 높게 나온 것으로 추정할 수 있다.

Table 7. Correlation Analysis between CR-10 result and Muscle strength

\begin{tabular}{c|c|c|c|c}
\hline \multirow{2}{*}{$\begin{array}{c}\text { 오른쪽 } \\
\text { 대퇴사두근 }\end{array}$} & $\begin{array}{c}\text { 오른쪽 } \\
\text { 윗다리 }\end{array}$ & $\begin{array}{c}\text { 왼쪽 } \\
\text { 윗다리 }\end{array}$ & $\begin{array}{c}\text { 오른쪽 } \\
\text { 아랫다리 }\end{array}$ & $\begin{array}{c}\text { 왼쪽 } \\
\text { 아랫다리 }\end{array}$ \\
\cline { 2 - 5 } & 0.011 & 0.095 & 0.304 & 0.263 \\
\hline \multirow{2}{*}{ 왼쪽 } & 0.018 & 0.059 & $<.0001$ & $<.0001$ \\
\cline { 2 - 5 } 되사두근 & 0.717 & 0.098 & 0.217 & 0.165 \\
\hline 오른쪽 & 0.179 & 0.275 & 0.306 & 0.282 \\
\cline { 2 - 5 } 비복근 & 0.000 & $<.0001$ & $<.0001^{* *}$ & $<.0001$ \\
\hline \multirow{2}{*}{ 왼쪽 } & -0.005 & 0.137 & 0.097 & 0.073 \\
\cline { 2 - 5 } 비곤근 & 0.918 & 0.006 & 0.053 & 0.146 \\
\hline \multirow{2}{*}{ 오른쪽 } & 0.172 & 0.176 & 0.298 & 0.266 \\
\cline { 2 - 5 } 전경골근 & 0.001 & 0.000 & $<.0001^{* *}$ & $<.0001$ \\
\hline \multirow{2}{*}{$\begin{array}{c}\text { 왼쪽 } \\
\text { 전경골근 }\end{array}$} & 0.207 & 0.207 & 0.325 & 0.307 \\
\cline { 2 - 5 } & $<.0001$ & $<.0001$ & $<.0001$ & $<.0001^{* *}$ \\
\hline
\end{tabular}

\subsection{EMG result}

\subsubsection{Retus Femoris}

오른쪽 대퇴직근에 대해서 하지 불균형 자세 $(\mathrm{P})$, 시간 $(\mathrm{T})$, 발판 높이(D)에 따른 근활성도의 분산분석 결과는 <Table 8>와 같다. <Table 8>에서 나타난 바와 같이 오른쪽 대퇴직 근의 경우 하지 자세에 대해서만 유의하게 나타났으며, 시간 및 발판 높이 등의 인자 및 교호작용에 대해서는 유의하지 않게 나타났다 $(\alpha=0.01)$.

<Table 9>은 하지 불균형 자세에 대한 TUKEY의 다중 범위 검정한 결과이다. 오른쪽 대퇴직근의 경우 무릎 앉은 
자세 및 쪼그려 앉은 자세에 비해 선 자세가 A그룹으로 가 장 높은 근육 활성도가 나타났다. 이 결과는 앞에서 언급한 오른쪽 윗다리에 대한 주관적 불편도와 동일한 결과가 나타 났다. 따라서 선 자세의 경우 오른발에 체중을 집중시킴으로 써 다른 자세에 비해 대퇴직근의 활성도가 높음에 따라 주관 적 불편도 또한 높게 나옴을 추정할 수 있다.

Table 8. ANOVA for RMS on Retus Femoris by posture, time and height of scaffold

\begin{tabular}{c|r|r|r|r|c}
\hline Source & \multicolumn{1}{|c|}{$\mathrm{DF}$} & \multicolumn{1}{c|}{$\mathrm{SS}$} & \multicolumn{1}{c|}{$\mathrm{MS}$} & $\mathrm{F}$ value & $\mathrm{Pr}>\mathrm{F}$ \\
\hline $\mathrm{P}$ & 3 & 18077.08 & 6025.69 & 23.36 & $<.0001^{* *}$ \\
\hline $\mathrm{T}$ & 3 & 40.52 & 13.51 & 0.05 & 0.9842 \\
\hline $\mathrm{D}$ & 2 & 849.60 & 424.80 & 1.65 & 0.1942 \\
\hline $\mathrm{P} * \mathrm{~T}$ & 9 & 165.71 & 18.41 & 0.07 & 0.9999 \\
\hline $\mathrm{T} * \mathrm{D}$ & 6 & 272.06 & 45.34 & 0.18 & 0.9833 \\
\hline $\mathrm{P} * \mathrm{D}$ & 4 & 0.00 & 0.00 & 0.00 & 1.0000 \\
\hline $\mathrm{P} * \mathrm{~T} * \mathrm{D}$ & 12 & 235.65 & 19.64 & 0.08 & 1.0000 \\
\hline ERROR & 360 & 92879.70 & 258.00 & & \\
\hline TOTAL & 399 & 112176.99 & & & \\
\hline
\end{tabular}

Table 9. TUKERY's test for posture on Retus Femoris

\begin{tabular}{c|c|c|c|c}
\hline \multicolumn{2}{l|}{ TUKEY GROUPING } & MEAN & $\mathrm{N}$ & \multicolumn{1}{c|}{ POSTURE } \\
\hline $\mathrm{A}$ & & 19.721 & 120 & STANDING \\
\hline & $\mathrm{B}$ & 6.726 & 120 & BENDING \\
\hline & $\mathrm{B}$ & 4.810 & 120 & SQUATTING \\
\hline & $\mathrm{B}$ & 2.458 & 40 & SITTING \\
\hline
\end{tabular}

\subsubsection{Vastus Lateralis}

오른쪽 외측광근에 대해서 하지 불균형 자세 $(\mathrm{P})$, 시간 $(\mathrm{T})$, 발판 높이(D)에 따른 근활성도의 분산분석 결과는 <Table 10 >와 같다. <Table 10>에서 나타난 바와 같이 오른쪽 외측광근의 경우 하지 자세에 대해서만 유의하게 나타났다 ( $\alpha=0.01$ ).

<Table 11 >은 하지 불균형 자세에 대한 TUKEY의 다중 범위 검정한 결과이다. 외측광근의 경우 대퇴직근과 함께 대 퇴사두근 중에 하나로 슬관절의 신전에 동일하게 작용하여 대퇴직근과 마찬가지로 무릎 앉은 자세 및 쪼그려 앉은 자세 에 비해 선 자세에서 가장 높은 근육 활성도가 나타났다. 이 결과는 앞에서 언급한 오른쪽 윗다리에 대한 주관적 불편도 와 동일한 결과다. 따라서 선 자세의 경우 오른발에 체중을 집중시킨 결과 다른 자세에 비해 대퇴직근 및 외측광근의 활성도가 높음에 따라 주관적 불편도 또한 높게 나옴을 추정 할 수 있다.
Table 10. ANOVA for RMS on Vastus Lateralis by posture, time and height of scaffold

\begin{tabular}{c|r|r|r|r|c}
\hline Source & DF & \multicolumn{1}{c|}{ SS } & \multicolumn{1}{c|}{ MS } & F value & Pr $>\mathrm{F}$ \\
\hline $\mathrm{P}$ & 3 & 52448.36 & 17482.79 & 27.90 & $<.0001^{* *}$ \\
\hline $\mathrm{T}$ & 3 & 122.01 & 40.67 & 0.06 & 0.9784 \\
\hline $\mathrm{D}$ & 2 & 818.56 & 409.28 & 0.65 & 0.5210 \\
\hline $\mathrm{P} * \mathrm{~T}$ & 9 & 275.04 & 30.56 & 0.05 & 1.0000 \\
\hline $\mathrm{T} * \mathrm{D}$ & 6 & 100.76 & 16.79 & 0.03 & 0.9999 \\
\hline $\mathrm{P}^{*} \mathrm{D}$ & 4 & 897.08 & 224.27 & 0.36 & 0.8384 \\
\hline $\mathrm{P} \mathrm{T}^{*} \mathrm{D}$ & 12 & 208.49 & 17.38 & 0.03 & 1.0000 \\
\hline ERROR & 360 & 225545.16 & 626.51 & & \\
\hline TOTAL & 399 & 280415.45 & & & \\
\hline
\end{tabular}

Table 11. TUKERY's test for posture on Vastus Lateralis

\begin{tabular}{c|c|r|r|c}
\hline \multicolumn{2}{c|}{ TUKEY GROUPING } & MEAN & \multicolumn{1}{c|}{$\mathrm{N}$} & POSTURE \\
\hline $\mathrm{A}$ & & 30.842 & 120 & STANDING \\
\hline & $\mathrm{B}$ & 9.143 & 120 & BENDING \\
\hline & $\mathrm{B}$ & 4.596 & 120 & SQUATTING \\
\hline & $\mathrm{B}$ & 2.806 & 40 & SITTING \\
\hline
\end{tabular}

\subsubsection{Gastrocnemius}

오른쪽 비복근에 대해서 하지 불균형 자세 $(\mathrm{P})$, 시간 $(\mathrm{T})$, 발판 높이(D) 등에 따른 근활성도의 분산분석 결과는 <Table 12 >와 같다. <Table 12 >와 같이 오른쪽 비복근의 경우 하지 자세에 대해서만 유의하게 나타났고, 시간 및 발 판 높이 등의 인자에 대해서는 유의하지 않게 나타났다 $(\alpha$ $=0.01$ ).

Table 12. ANOVA for RMS on Gastrocnemius by posture, time and height of scaffold

\begin{tabular}{c|r|r|r|c|c}
\hline Source & DF & \multicolumn{1}{c|}{ SS } & \multicolumn{1}{c|}{ MS } & F value & $\operatorname{Pr}>\mathrm{F}$ \\
\hline $\mathrm{P}$ & 3 & 3635.01 & 1211.67 & 13.27 & $<.0001^{* *}$ \\
\hline $\mathrm{T}$ & 3 & 61.21 & 20.40 & 0.22 & 0.8801 \\
\hline $\mathrm{D}$ & 2 & 238.69 & 119.34 & 1.31 & 0.2719 \\
\hline $\mathrm{P} * \mathrm{~T}$ & 9 & 67.82 & 7.54 & 0.08 & 0.9998 \\
\hline $\mathrm{T} * \mathrm{D}$ & 6 & 81.13 & 13.52 & 0.15 & 0.9894 \\
\hline $\mathrm{P} * \mathrm{D}$ & 4 & 839.48 & 209.87 & 2.30 & 0.0586 \\
\hline $\mathrm{P} \mathrm{T}^{*} \mathrm{D}$ & 12 & 99.52 & 8.29 & 0.09 & 1.0000 \\
\hline ERROR & 360 & 32871.48 & 91.31 & & \\
\hline TOTAL & 399 & 37894.34 & & & \\
\hline
\end{tabular}

<Table 13>은 하지 불균형 자세에 대한 TUKEY의 다중 
범위 검정한 결과이다. 오른쪽 비복근의 경우 선 자세와 쪼 그려 앉은 자세 등의 경우 $\mathrm{A}$ 그룹, 무릎 앉은 자세의 경우 $\mathrm{B}$ 그룹으로 나타났다. 선 자세의 경우 체중이 오른발에 집중 됨에 따라 비복근의 근활성도가 가장 높게 나타났고, 쪼그 려 앉은 자세의 경우 자세 유지를 위해 근활성도가 지속적 으로 나타났다. 이에 반해 무릎 앉은 자세에서 오른발의 경 우 발목관절에서 배측굴곡이 일어남에 따라 발목관절의 저 측굴곡에 작용하는 비복근의 활성도가 비교적 낮은 것으로 추정할 수 있다.

Table 13. TUKERY's test for posture on Gastrocnemius

\begin{tabular}{c|c|r|r|c}
\hline \multicolumn{2}{l|}{ TUKEY GROUPING } & \multicolumn{1}{c|}{ MEAN } & \multicolumn{1}{c|}{ N } & POSTURE \\
\hline $\mathrm{A}$ & & 11.551 & 120 & STANDING \\
\hline $\mathrm{A}$ & & 9.694 & 120 & SQUATTING \\
\hline & $\mathrm{B}$ & 5.636 & 120 & BENDING \\
\hline & $\mathrm{B}$ & 2.637 & 40 & SITTING \\
\hline
\end{tabular}

\subsubsection{Tibialis Anterior}

오른쪽 전경골근에 대해서 하지 불균형 자세 $(\mathrm{P})$, 시간 ( $\mathrm{T}$, 발판 높이 $(\mathrm{D})$ 등에 따른 근활성도의 분산분석 결과는 <Table 14>와 같다. <Table 14>에서 나타난 바와 같이 오 른쪽 전경골근의 경우 하지 자세에 대한 주효과에 대해서만 유의하게 나타났고, 나머지 인자에 대해서는 유의하지 않게 나타났다 ( $\alpha=0.01)$.

Table 14. ANOVA for RMS on Tibialis Anterior by posture, time and height of scaffold

\begin{tabular}{c|r|r|r|r|c}
\hline Source & DF & \multicolumn{1}{c|}{ SS } & \multicolumn{1}{c|}{ MS } & F value & $\operatorname{Pr}>\mathrm{F}$ \\
\hline $\mathrm{P}$ & 3 & 113730.31 & 37910.10 & 20.05 & $<.0001^{* *}$ \\
\hline $\mathrm{T}$ & 3 & 2222.01 & 740.67 & 0.39 & 0.7590 \\
\hline $\mathrm{D}$ & 2 & 7468.30 & 3734.15 & 1.98 & 0.1402 \\
\hline $\mathrm{P} * \mathrm{~T}$ & 9 & 2782.61 & 309.18 & 0.16 & 0.9973 \\
\hline $\mathrm{T} * \mathrm{D}$ & 6 & 508.25 & 84.71 & 0.04 & 0.9996 \\
\hline $\mathrm{P} * \mathrm{D}$ & 4 & 0.00 & 0.00 & 0.00 & 1.0000 \\
\hline $\mathrm{P} * \mathrm{~T} * \mathrm{D}$ & 12 & 939.03 & 78.25 & 0.04 & 1.0000 \\
\hline ERROR & 360 & 680551.19 & 1890.42 & & \\
\hline TOTAL & 399 & 807719.71 & & & \\
\hline
\end{tabular}

<Table 15>은 하지 불균형 자세에 대한 TUKEY의 다중 범위 검정한 결과이다. 오른쪽 전경골근의 경우 오른쪽 아랫 다리와 마찬가지로 쪼그려 앉은 자세에서 가장 높은 근활성 도가 나타났다. 따라서 쪼그려 앉은 자세의 경우 8 분간 일
정한 자세를 지속적으로 유지하기 위해 전경골근의 활성도 가 높음에 따라 주관적 불편도가 높게 나타남을 추정할 수 있다.

Table 15. TUKERY's test for posture on Tibialis Anterior

\begin{tabular}{c|c|c|r|r|c}
\hline \multicolumn{2}{l|}{ TUKEY GROUPING } & \multicolumn{1}{c|}{ MEAN } & N & POSTURE \\
\hline A & & & 47.901 & 120 & SQUATTING \\
\hline & $\mathrm{B}$ & & 21.940 & 120 & BENDING \\
\hline & $\mathrm{B}$ & $\mathrm{C}$ & 9.129 & 120 & STANDING \\
\hline & & $\mathrm{C}$ & 2.707 & 40 & SITTING \\
\hline
\end{tabular}

\subsection{The relationship between CR-10 result and EMG result}

\subsubsection{Upper leg}

피실험자의 주관적 불편도의 윗다리(UPPER)와 EMG의 결과 값인 대퇴직근(RT) 및 외측광근(VLO) 등의 RMS 값 에 대한 상관관계분석 결과는 <Table 16 >와 같다. 윗다리의 경우 주관적 불편도의 값과 $\mathrm{RMS}$ 의 값은 통계적으로 상관 관계가 있는 것으로 나타났고 대퇴직근의 경우 상관계수가 0.48423 , 비복근의 경우 상관계수가 0.52197로 나타났다. 이것은 앞에서 언급한 바와 같이 윗다리의 주관적 불편도와 퇴직근 및 외측광근 등의 RMS 값이 동일한 결과를 보인 것에 대한 것으로 추정할 수 있다.

Table 16. Correlation Analysis between CR-10 on upper leg and RMS on Retus Femoris and Vastus Lateralis

\begin{tabular}{c|c|c|c}
\hline & UPPER & RT & VLO \\
\hline \multirow{2}{*}{ UPPER } & 1.00000 & 0.48423 & 0.52197 \\
\cline { 2 - 4 } & & $0.0015^{* *}$ & $0.0006^{* *}$ \\
\hline \multirow{2}{*}{ RT } & 0.48423 & 1.00000 & 0.95635 \\
\cline { 2 - 4 } & $0.0015^{* *}$ & & $<.0 .0001^{* *}$ \\
\hline \multirow{2}{*}{ VLO } & 0.52197 & 0.95635 & 1.00000 \\
\cline { 2 - 4 } & $0.0006^{* *}$ & $<.0 .0001^{* *}$ & \\
\hline
\end{tabular}

\subsubsection{Lower leg}

피실험자의 주관적 불편도의 아랫다리(LOWER) 와 EMG 의 결과 값인 비복근 $(\mathrm{GA})$ 및 전경골근 $(\mathrm{TI})$ 등의 RMS 값 에 대한 상관관계분석의 결과는 <Table $17>$ 와 같다. 아랫다 리와 비복근의 경우 통계적으로 유의하지 않게 나타났으며, 전경골근의 경우 상관관계가 있는 것으로 나타났다. 아랫다 리 및 전경골근의 경우 쪼그려 앉은 자세에서 불편도가 가장 높게 나타난 반면, 비복근의 경우 선 자세에서 가장 높은 근 
활성도가 나타난 것과 같이 주관적 불편도 및 전경골근의 경 우 같은 결과를 보인 것에 비해, 비복근의 경우 다른 결과를 보인 것에 대한 것으로 추정할 수 있다.

Table 17. Correlation Analysis between CR-10 on lower leg and RMS on Gastrocnemius and Tibialis Anterior

\begin{tabular}{c|c|c|c}
\hline & R_LOWER & RT_GA & RT_TI \\
\hline \multirow{2}{*}{ R_LOWER } & 1.00000 & 0.23470 & 0.42048 \\
\cline { 2 - 4 } & & 0.1449 & $0.0069^{* *}$ \\
\hline \multirow{3}{*}{ RT_GA } & 0.23470 & 1.00000 & 0.08631 \\
\cline { 2 - 4 } & & & \\
\cline { 2 - 4 } & 0.1449 & & 0.5964 \\
\hline \multirow{2}{*}{ RT_TI } & 0.42048 & 0.08631 & 1.00000 \\
\cline { 2 - 4 } & $0.0069^{* *}$ & 0.5964 & \\
\hline
\end{tabular}

\subsection{Multiple regression analysis result for posture}

\subsubsection{Standing posture}

<Table 18>은 주관적 불편도에 대한 선 자세에서 신 체 조건(키, 몸무게, 위앞엉덩이뼈가시높이, 무릎 높이, 발 직선길이, 발너비)과 시간에 따른 다중회귀분석(multiple regression analysis)을 실시한 결과이다. 모형 선택(model selection) 방법으로는 단계적 방법(stepwise methods)을 적용하였고, 그 결과 무릎 높이, 발 직선길이, 시간 등의 변수에서 유의하게 나타났으며, $\mathrm{R}^{2}=0.4213$ 으로 나타나 선 자세에 대한 주관적 불편도에 대한 관련 변인의 영향을 $42.13 \%$ 설명하는 것으로 나타났다. 최종적으로 적합된 모 형은 수식 (1) 과 같다.

Table 18. Multiple regression analysis for standing posture by physical condition and time

\begin{tabular}{c|c|c|c|c|c}
\hline Variable & $\begin{array}{c}\text { Parameter } \\
\text { estimate }\end{array}$ & $\begin{array}{c}\text { Type II } \\
\text { SS }\end{array}$ & $\begin{array}{c}\text { F } \\
\text { value }\end{array}$ & \multirow{2}{*}{$\mathrm{R}^{2}$} & $\operatorname{Pr}>\mathrm{F}$ \\
\hline INTERCEPT & -4.443 & 1.253 & 4.06 & \multirow{3}{*}{0.4213} & $0.046^{*}$ \\
\cline { 1 - 4 } \cline { 3 - 4 } KNEE & 0.031 & 7.248 & 23.49 & $<.0001^{* *}$ \\
\hline FOOT & -0.045 & 9.622 & 31.18 & & $<.0001^{* *}$ \\
\cline { 1 - 3 } TIME & 0.162 & 15.746 & 51.03 & & $<.0001^{* *}$ \\
\hline
\end{tabular}

$$
\begin{gathered}
\hat{y}=\frac{10 \times e^{-4.443+0.031 x_{1}-0.045 x_{2}+0.162 x_{3}}}{1+e^{-4.443+0.031 x_{1}-0.045 x_{2}+0.162 x_{3}}} \\
x_{1}=\text { 무릎높이 }(\mathrm{mm}) \\
x_{2}=\text { 발직선 길이 }(\mathrm{mm}) \\
x_{3}=\text { 시간 }(\text { 분 })
\end{gathered}
$$

\subsubsection{Squatting posture}

<Table 19>는 주관적 불편도에 대한 쪼그려 앉은 자세 에서 신체 조건(키, 몸무게, 다리 길이, 무릎 높이, 발 직선 길이, 발 너비)과 시간, 발판 높이 등에 따른 다중회귀분석 (multiple regression analysis)을 실시한 결과이다. 모형 선택(model selection) 방법으로는 단계적 방법(stepwise methods)을 적용하였고, 그 결과 키, 다리 길이, 무릎 높이, 시간, 발판 높이 등의 변수에서 유의하게 나타났으며, $\mathrm{R}^{2}=$ 0.5081으로 나타나 쪼그려 앉은 자세에 대한 주관적 불편도 에 대한 관련 변인의 영향을 $50.81 \%$ 설명하는 것으로 나타

\begin{tabular}{|c|c|c|c|c|c|}
\hline Variable & $\begin{array}{c}\text { Parameter } \\
\text { estimate }\end{array}$ & $\begin{array}{c}\text { Type II } \\
\text { SS }\end{array}$ & $\begin{array}{c}\mathrm{F} \\
\text { value }\end{array}$ & $\mathrm{R}^{2}$ & $\operatorname{Pr}>F$ \\
\hline INTERCEPT & 2.626 & 0.403 & 1.37 & \multirow{6}{*}{0.5081} & 0.2444 \\
\hline HEIGH & -0.004 & 2.083 & 7.07 & & $0.0089^{* *}$ \\
\hline LEG & 0.026 & 4.338 & 14.74 & & $0.0002^{* *}$ \\
\hline KNEE & -0.09 & 6.534 & 22.20 & & $<.0001^{* *}$ \\
\hline TIME & 0.174 & 18.262 & 62.03 & & $<.0001^{* *}$ \\
\hline DISPARITY & 0.024 & 4.428 & 15.04 & & $0.0002^{* *}$ \\
\hline
\end{tabular}
났다. 최종적으로 적합된 모형은 수식 (2)과 같다.

Table 19. Multiple regression analysis for squatting posture by physical condition, time and height of scaffold

$$
\begin{aligned}
\hat{y}=\frac{10 \times e^{2.626-0.004 x_{1}+0.026 x_{2}-0.009 x_{3}+0.174 x_{4}+0.024 x_{6}}}{1+e^{2.626-0.004 x_{1}+0.026 x_{2}-0.009 x_{3}+0.174 x_{4}+0.024 x_{6}}} \\
\left.x_{1}=7\right](\mathrm{mm}) \\
x_{2}=\text { 무릎높이 }(\mathrm{mm}) \\
x_{3}=\text { 위핲엉 덩이 빼가시높이 }(\mathrm{mm}) \\
x_{4}=\text { 시간 }(\text { 분 }) \\
x_{5}=\text { 발판 높이 }(\mathrm{cm})
\end{aligned}
$$

\subsubsection{Bending posture}

<Table 20>은 주관적 불편도에 대한 무릎 앉은 자세에서 신체 조건(키, 몸무게, 다리 길이, 무릎 높이, 발 직선길이, 발 너비) 및 시간에 따른 다중회귀분석 (multiple regression analysis)을 실시한 결과이다. 모형 선택(model selection) 방법으로는 단계적 방법(stepwise methods)을 적용하였고, 그 결과 몸무게, 키, 다리 길이, 무릎 높이, 발 직선길이, 시 간 등의 변수에서 유의하게 나타났으며, $\mathrm{R}^{2}=0.6986$ 으로 나 타나 쪼그려 앉은 자세에 대한 주관적 불편도에 대한 관련 
변인의 영향을 $69.86 \%$ 설명하는 것으로 나타났다.

최종적으로 적합된 모형은 수식 (3) 과 같다.

Table 20. Multiple regression analysis for bending posture by physical condition and time

\begin{tabular}{|c|c|c|c|c|c|}
\hline Variable & $\begin{array}{c}\text { Parameter } \\
\text { estimate }\end{array}$ & $\begin{array}{c}\text { Type II } \\
\text { SS }\end{array}$ & $\begin{array}{c}F \\
\text { value }\end{array}$ & $\mathrm{R}^{2}$ & $\operatorname{Pr}>F$ \\
\hline INTERCEPT & 1.076 & 0.056 & 0.14 & \multirow{7}{*}{0.6986} & 0.7134 \\
\hline WEIGHT & 0.021 & 2.014 & 4.90 & & $0.0288^{*}$ \\
\hline HEIGH & -0.014 & 5.707 & 13.89 & & $0.0003^{* *}$ \\
\hline LEG & 0.108 & 53.993 & 131.17 & & $<.0001^{* *}$ \\
\hline KNEE & -0.018 & 22.600 & 55.01 & & $<.0001^{* *}$ \\
\hline FOOT & -0.054 & 9.117 & 22.46 & & $<.0001^{* *}$ \\
\hline TIME & 0.194 & 22.647 & 55.13 & & $<.0001^{* *}$ \\
\hline
\end{tabular}

$$
\begin{aligned}
\hat{y}=\frac{10 \times e^{1.076+0.021 x_{1}-0.014 x_{2}+0.108 x_{3}-0.018 x_{4}-0.054 x_{6}+0.194 x_{6}}}{1+e^{1.076+0.021 x_{1}-0.014 x_{2}+0.108 x_{3}-0.018 x_{4}-0.054 x_{6}+0.194 x_{6}}} \\
x_{1}=\text { 몸무게 }(\mathrm{kg}) \\
x_{2}=\text { 키 }(\mathrm{mm}) \\
x_{3}=\text { 무룦높이 }(\mathrm{mm}) \\
x_{4}=\text { 위핲엉덩이벼가시높이 }(\mathrm{mm}) \\
x_{5}=\text { 발직선길이 }(\mathrm{mm}) \\
\left.x_{6}=\text { 시간(분 }\right)
\end{aligned}
$$

\section{Conclusion and Discussion}

본 연구에서는 우리나라의 작업 특성상 작업자들이 많이 취하고 있는 하지 불균형 자세에 대해 주요 근육의 활성도와 주요 부위의 주관적 불편도를 평가함으로써 다양한 하지 자 세간의 부하 수준을 비교 및 작업 지속시간에 대한 인간공학 적 작업 지침을 제시하기 위한 평가를 실시하고자 하였다. 또한, 본 연구에서는 하지 불균형 자세에 대해 정성적 평가 인 주관적 불편도의 평가를 실시하였으나 이 방법은 정량적 인 측면에서 단점을 가지고 있음에 따라 정량적 데이터인 $\mathrm{EMG}$ 를 이용한 생리학적 분석 기법을 통하여 주관적 불편도 의 결과를 검증하였다. 그 결과 주관적 불편도 평가가 정량 적인 평가 기법들의 결과값과 상관관계가 있는 것으로 나타 났으며, 정적 작업부하 평가에 적합함을 증명하였다.

본 연구의 결과 선 자세 및 쪼그려 앉은 자세의 경우 6 분 이상, 무릎 앉은 자세의 경우 4 분 이상 유지하는 것을 지양 해야 하며 오른발 왼발의 높이의 차는 선 자세를 제외하고
는 $20 \mathrm{~cm}$ 이상인 경우는 지양해야 한다고 볼 수 있다.

이러한 결과는 작업 환경 및 작업방법의 설계와 평가에 활용할 수가 있을 것이며, 작업현장에서 쪼그려 앉은 자세 및 무를 꼻은 자세 등의 하지에 관한 작업 자세에 대한 인간 공학적 지침을 제시하는데 유용한 자료가 될 것으로 기대된 다. 또한, 자세의 피로와 통증을 예방하기 위한 기초자료로 이용되며, 다양한 작업 자세에 대한 정량적 평가 모델 구축 함에 있어 유용한 기초자료가 될 것으로 기대된다.

본 연구는 실험실 내의 환경에서 실험이 이루어짐에 따라 실제 작업 환경에 일반화시켜 적용하는 데에는 제한이 있으 며, 참여한 피실험자들은 모두 현장의 작업경험이 없는 학생 들을 대상으로 제한되었다. 또한, 실제 작업현장의 경우 불 균형 및 작업시간 외에 다른 변수 및 자세들이 실제로 이루 어져 수행되고 있음에 따라 이러한 하지 작업 자세들에 대 해 불균형 및 작업시간 외에 다른 변수를 고려한 세부적인 연구가 이루어져야 할 것이다.

\section{Acknowledgements}

This work was supported by Dong-A University research fund.

\section{References}

Baker, P., Reading, I., Cooper, C. and Coggon, D., "Knee disorders in the general population and their relation to occupation," Occupational and Environmental Medicine, 60(10), pp. 794-797, 2003.

Basmajin, J. V., "Muscles Alive - Their Functions Revealed by Electromyography." Williams \& Wilkins, (1978).

Hong, C.-W. and Kim, Y.-C., "The Evaluation of Workload on Lower Limbs Muscles in Imbalanced Lower Limbs Postures Using EMG for Preventing WMSDs", Journal of the Ergonomics Society of Korea, Vol. 28, No. 3 pp.81-85, 2009.

Coggon, D., Croft, P., Kellingray, S., Barrett, D., McLaren, M. and Cooper, C., "Occupational physical activities and osteoarthritis of the knee," Arthritis and Rheumatism, 43(7), pp. 1443-1449, 2000.

Cooper, C., McAlindon, T., Coggon, D., Egger, P. and Dieppe, P., "Occupational activity and osteoarthritis of the knee," Annals of Rheumatology and Diseases, 53(2), pp. 90-93, 1994.

Gallagher, S., Marras, W. S. and Bobick, T. G., "Lifting in stooped and kneeling postures: effects on lifting capacity, metabolic costs, and electromyography of eight trunk muscles," International Journal of Industrial Ergonomics, 3(1), pp. 65-76, 1988.

Genaidy, A. M., Barkawi, H. and Christensen, D., "Ranking of static non-neutral postures around the joints of the upper extremity and the 
spine", Ergonomics, 38(9), 1851-1958, 1995.

Grandjean, E. and Hüunting, W., "Ergonomics of postures - review of various problems of standing and sitting postures," Applied Ergonomics, 8(3), pp.135-140, 1977.

Lee, I.-S. and Chung, M.-K., "Workload Evaluation of Squatting Work Postures", Journal of the Korean Institute of Industrial Engineers, 24(2), pp. 167-173, 1998.

Jensen, L. K. and Eenberg, W., "Occupation as a risk factor for knee disorders," Scandinavian Journal of Work Environment and Health, 22(3), pp. 165-175, 1996.

Ministry of Employment and Labor of Korea, The report on occupational accident and disease statistics, 2001-2007.

Nahit, E. S., Macfarlane, G. J., Pritchard, C. M., Cherry, N. M. and Silman, A. J., "Short-term influence of mechanical factors on regional musculoskeletal pain: A study of new workers from 12 occupational groups," Occupational and Environmental Medicine, 58, pp. 374-381, 2001.

Oberg, T., Sandsjo, L. and Kadefors, R., "Subjective and objective evaluation of shoulder muscle fatigue", Ergonomics, 37(8), 1323-1333, 1994.

Okunribido, O., "Lower limb MSD-scoping work in help inform advice and research planning," Health and Safety Excutive(HSE), 2009.

Peter, K., "The ABC of EMG - A Practical Introduction to Kinesiological Electromyography." Noraxon INC. USA. (2005).

U.S Department of Labor, Bureau of Labor Statistics, 2001-2007.

van Wely, P., "Design and disease," Applied Ergonomics, 1(5), pp. 262-269, 1970.

Westgaard, R. H. and Aaråas, A., "Postural muscle strain as a causal factor in the development of musculoskeletal illnesses," Applied Ergonomics, 15(3), pp. 162-174, 1984.

Zhang, Y., Hunter, D. J., Nevitt, M. C., Xu, L., Niu, J., Lui, L. Y., Yu, W.,

\begin{abstract}
Aliabadi, P. and Felson, D. T., "Association of squatting with increased prevalence of radiographic tibiofemoral knee osteoarthritis - The Beijing osteoarthritis study" Arthritis and Rheumatism, 50(4), pp. 1187-1192, 2004.
\end{abstract}

\section{Author listings}

Eun-Sik Kim: kimeunsik83@gmail.com

Highest degree: MS, Department of Industrial and Management Systems Engineering, Dong-A University

Position title: Research Assistant, Department of Industrial and

Management Systems Engineering, Dong-A University

Areas of interest: Industrial ergonomics, biomechanics, $\mathrm{HCI}$

Hoon-Yong Yoon: yhyoon@dau.ac.kr

Highest degree: $\mathrm{PhD}$, Department of Industrial Engineering, Texas Tech Position title: Professor, Department of Industrial and Management Systems Engineering, Dong-A University

Areas of interest: Industrial ergonomics, Product development and evaluation, Organizational Behavior

Date Received : 2011-07-17

Date Revised :2011-07-25

Date Accepted : 2011-07-25 